\title{
PROPRIEDADE FAMILIAR E DESEMPENHO DE EMPRESAS DO AGRONEGÓCIO BRASILEIRO
}

\author{
Jaqueline Carla Guse* \\ Leandro Politelo** \\ Maurício Leite ${ }^{* * *}$ \\ Tarcísio Pedro da Silva****
}

RESUMO: O agronegócio desempenha um papel significativo no cenário econômico e financeiro no Brasil. Esta pesquisa objetiva verificar a relação da propriedade familiar com o desempenho de empresas do agronegócio brasileiro. Para tanto é aplicada uma pesquisa descritiva com abordagem quantitativa em uma amostra de 25 empresas listadas na BM\&FBovespa no período de 2010 a 2012. A Análise Envoltória de Dados (DEA) é aplicada para identificar a eficiência quanto ao desempenho das empresas familiares e não familiares, e a técnica estatística ANOVA para se verificar se as empresas familiares apresentavam maior ou menor eficiência em relação ao seu desempenho quando comparadas às empresas não familiares. Os resultados da pesquisa indicam que as empresas Excelsior, Iguaçu Café, Laep e Renar foram eficientes nos três anos analisados tanto em seus grupos (familiar ou não familiar) quanto em relação à amostra total. As empresas Tereos, Cacique e Josapar apresentaram-se como as menos eficientes. Apesar de não significativos, os resultados apresentam indicativos de que as empresas não familiares são mais eficientes que as empresas familiares quanto ao desempenho de curto prazo.

PALAVRAS-CHAVE: Agronegócio; Desempenho; Empresas Familiares.

\section{FAMILIAL PROPERTY AND THE PERFORMANCE OF BRAZILIAN AGRIBUSINESS COMPANIES}

ABSTRACT: Agribusiness has a significant role in Brazilian economic and financial situation. Current research registers the relationship between familial property and the performance of Brazilian agribusiness companies. A descriptive research cou-

\footnotetext{
"Mestre em Ciências Contábeis (FURB), Blumenau (SC), Brasil.

${ }^{* *}$ Mestre em Ciências Contábeis (FURB), Blumenau (SC), Brasil.

**** Mestre em Ciências Contábeis (FURB), Blumenau (SC), Brasil.

${ }^{* * * * *}$ Programa de Pós-Graduação em Ciências Contábeis (FURB), Blumenau (SC), Brasil;

E-mail: tarcisio@furb.br
} 
pled to a quantitative approach is applied in a sample comprising 25 companies on the BM\&FBovespa between 2010 and 2012. Data Envelopment Analysis (DEA) identifies the efficiency of performance of familial and non-familial companies, whereas the statistical analysis ANOVA verifies whether familial companies have a greater or smaller efficiency with regard to performance when compared to non-familial enterprises. Results reveal that the companies Excelsior, Iguaçu Café, Laep and Renar were efficient during the three years in which they were investigated with regard to their groups (familial and non-familial) and to their relationship to the sample as a whole. The companies Tereos, Cacique and Josapar had the lowest efficiency. Results, albeit not significant, indicate that non-familial companies are more efficient than familial ones in short term performance

KEY WORDS: Agribusiness; Performance; Familial Enterprises.

\section{INTRODUÇÃO}

O agronegócio tem desempenhado um importante papel econômico e financeiro no Brasil, contribuindo para o seu desenvolvimento e crescimento, com uma expressiva participação no Produto Interno Bruto (PIB). Segundo dados do Centro de Estudos Avançados em Economia Aplicada (CEPEA, 2012), divulgados no seu relatório PIB do Agronegócio - Dados de 1994 a 2011, o agronegócio representou em 2011 mais de 22\% do Produto Interno Bruto (PIB) brasileiro.

O Brasil é um dos maiores e mais importantes fornecedores de alimentos do mundo e um dos mais competitivos no mercado internacional. Segundo o Departamento de Agricultura dos Estados Unidos (USDA, 2013), o Brasil é o terceiro maior exportador agrícola, ficando atrás apenas dos Estados Unidos e da União Europeia, além de apresentar um índice de desenvolvimento agrícola acima da média mundial. Além disso, à medida que o país continua a fazer investimentos significativos no setor agrícola e cada vez mais persegue políticas de incentivo à produção agrícola, o Brasil deverá ter uma presença em expansão nos mercados de exportação de commodities agrícolas, oferecendo forte concorrência para os exportadores norte-americanos.

Nota-se que nas últimas três décadas, o agronegócio brasileiro vem melhorando seu desempenho e gerando ganhos de produtividade, o que permite o 
equilíbrio na balança comercial e uma geração de divisas para o país (WANDERLEY; SILVA; LEAL, 2012). Dessa forma, devido à essa melhora de desempenho, torna-se importante a busca pela eficiência na gestão empresarial de empresas do agronegócio brasileiro, dada a notoriedade do setor no Brasil (PEREZ; FAMÁ, 2004). Um dos meios para isso é a análise de desempenho econômico-financeiro, que permite uma avaliação da empresa quanto suas atividades passadas e permite realizar um planejamento para ações futuras. Um bom desempenho econômico-financeiro retrata uma situação de sustentabilidade da empresa no meio em que atua (PEREZ; FAMÁ, 2004).

Acrescenta-se à discussão a relevante participação familiar nas companhias de capital aberto (SILVA; MAJLUF, 2008). Na Europa Ocidental, Faccio e Lang (2002) identificaram que a maioria das empresas de capital aberto mantém controle familiar. Nos Estados Unidos da América, Anderson e Reeb (2003) constataram que um terço das empresas americanas por eles pesquisadas era de característica familiar. No Brasil, Oro, Beuren e Hein (2009) identificaram que, de uma amostra de 145 empresas dentre as 500 maiores e melhores segundo classificação da revista Exame, $41 \%$ delas caracterizavam-se como familiar.

No contexto das empresas familiares, Shyu (2011) declara que os objetivos empresariais destas empresas são convergentes com os objetivos das famílias e, conforme o autor, um dos principais interesses familiares consiste em obter um bom desempenho. Os resultados de diferentes pesquisas dão apoio a este argumento como as pesquisas de Maury (2006) e Martínez, Stöhr e Quiroga (2007). Por outro lado, Saravanan (2009) reconhece que a presença da família em uma empresa pode prejudicar a companhia tendo em vista que a família pode priorizar seus interesses em detrimento dos interesses da empresa, descapitalizando-a, o que pode prejudicar sua continuidade.

Como característica positiva das empresas familiares, Chami (2001) destaca que as famílias consideram a empresa como um ativo a ser herdado pelos membros da família ou seus descendentes e não como uma riqueza para ser utilizada durante sua vida; assim, a sobrevivência da empresa é uma grande preocupação para as famílias. Acrescenta-se ainda que, conforme Shyu (2011), a família tende a perspectivas de investimentos de longo prazo dentro do contexto empresarial. Esta preocupação sugere que as empresas familiares têm uma maior probabilidade de maximizar o seu 
valor (SAN MARTIN-REYNA; DURAN-ENCALADA, 2012).

Dessa forma, instiga-se a realização deste estudo visando responder a seguinte questão problema: qual a relação entre a propriedade familiar e o desempenho econômico-financeiro em empresas do agronegócio brasileiro? Assim, o objetivo do estudo consiste em verificar a relação da propriedade familiar com o desempenho de empresas do agronegócio brasileiro.

A justificativa para a realização deste estudo reside na importância do agronegócio para a economia brasileira bem como a importância das empresas familiares para a formação do PIB do agronegócio (WANDERLEY; SILVA; LEAL, 2012). Buscouse também, com os resultados, contribuir com estudos relacionados com as empresas familiares e seu desempenho econômico-financeiro.

\section{MATERIAL E MÉTODOS}

Para verificar a relação da propriedade familiar com o desempenho econômico-financeiro de empresas do agronegócio brasileiro, realizou-se uma pesquisa descritiva, com abordagem quantitativa, por meio de pesquisa documental.

$\mathrm{O}$ aspecto descritivo é observado na discussão da propriedade familiar e o desempenho econômico-financeiro de empresas do agronegócio, apresentando assim, uma descrição da amostra analisada. Conforme Gil (2011), uma pesquisa descritiva tem como objetivo primordial a descrição das características de determinada população, fenômeno ou o estabelecimento de relações entre variáveis.

Quanto ao método, o estudo classifica-se como quantitativo em virtude do uso de instrumentos estatísticos nas fases de coleta, tratamento e análise dos dados, conforme preconiza Richardson (1999). Segundo Collis e Hussey (2005), esse método é mais objetivo, focado na mensuração de fenômenos e, para que isto ocorra a contento, usa-se de coleta de dados numéricos e aplicação de cálculos estatísticos.

Em relação aos procedimentos, classifica-se como pesquisa documental por utilizar-se de informações constantes nas demonstrações contábeis das empresas. No entendimento de Cervo, Berviam e Silva (2007), a pesquisa documental ou bibliográfica busca explicar um problema baseado em referências teóricas, sejam elas oriundas de livros, artigos publicados, dissertações ou teses. 


\subsection{POPULAÇÃO E AMOSTRA}

A população da pesquisa compreendeu as companhias abertas listadas no sub-setor de Agropecuária e Alimentos Processados do setor de Consumo Não Cíclico da BM\&FBovespa. A população compreendeu as 25 empresas do agronegócio de consumo não cíclico listadas na BM\&FBovespa, discriminadas conforme o Quadro1. Dessa forma, a amostra analisada é do tipo não probabilística, cuja característica principal é a de, não fazendo uso de formas aleatórias de seleção, torna-se impossível a aplicação de fórmulas estatísticas para o cálculo, conforme apontam Marconi e Lakatos (2012). Além disso, a amostra foi selecionada a partir do critério de conveniência. Gil (2011) destaca que na amostragem por acessibilidade ou por conveniência, o pesquisador seleciona elementos a que tem acesso, admitindo que estes, de alguma forma, representam o universo.

Quadro 1. Empresas do agronegócio de consumo não cíclico listadas na BM\&FBovespa.

(continua)

\begin{tabular}{|l|c|c|c|}
\hline Razão Social & $\begin{array}{c}\text { Nome de } \\
\text { Pregão }\end{array}$ & Segmento & Classificação \\
\hline Biosev S.A. & Biosev & Açúcar e Álcool & Não Familiar \\
\hline BRF S.A. & BRF S.A. & Carnes e Derivados & Não Familiar \\
\hline Café Solúvel Brasília S.A. & Café Brasília & Café & Familiar \\
\hline Cia Cacique de Café Solúvel & Cacique & Café & Não Familiar \\
\hline Cia Iguaçu de Café Solúvel & Iguaçu Café & Café & Não Familiar \\
\hline Clarion S.A. Agroindustrial & Clarion & Grãos e Derivados & Não Familiar \\
\hline Conservas Oderich S.A. & Oderich & Alimentos Diversos & Familiar \\
\hline Cosan Limited & Cosan Ltda & Açúcar e Álcool & Familiar \\
\hline Cosan S.A. Indústria e Comércio & Cosan & Açúcar e Álcool & Familiar \\
\hline Excelsior Alimentos S.A. & Excelsior & Carnes e Derivados & Não Familiar \\
\hline J. Macedo S.A. & J. Macedo & Alimentos Diversos & Familiar \\
\hline JBS S.A. & JBS S.A. & Carnes e Derivados & Familiar \\
\hline Josapar-Joaquim Oliveira S.A. Part. & Josapar & Alimentos Diversos & Familiar \\
\hline Laep Investments Ltd. & Laep & Laticínios & Familiar \\
\hline
\end{tabular}


(conclusão)

\begin{tabular}{|l|c|c|c|}
\hline M. Dias Branco S.A. Ind. Com. Alim. & M.Diasbranco & Alimentos Diversos & Familiar \\
\hline Marfrig Alimentos S.A. & Marfrig & Carnes e Derivados & Familiar \\
\hline Minerva S.A. & Minerva & Carnes e Derivados & Familiar \\
\hline Minupar Participações S.A. & Minupar & Carnes e Derivados & Não Familiar \\
\hline Monticiano Participações S.A. & Monticiano & Laticínios & Não Familiar \\
\hline Renar Macas S.A. & Renar & Agricultura & Familiar \\
\hline São Martinho S.A. & São Martinho & Açúcar e Álcool & Familiar \\
\hline SLC Agrícola S.A. & SLC Agrícola & Agricultura & Familiar \\
\hline Tereos Internacional S.A. & Tereos & Alimentos Diversos & Familiar \\
\hline Vanguarda Agro S.A. & V-Agro & Agricultura & Familiar \\
\hline Vigor Alimentos S.A. & Vigor & Laticínios & Familiar \\
\hline
\end{tabular}

Fonte: Dados da Pesquisa.

Para composição da amostra as empresas Vigor Alimentos S.A., Clarion S.A. Agroindustrial e Café Solúvel Brasília S.A. foram excluídas por terem aberto capital em exercício posterior a 2010, e a empresa Monticiano por não apresentar todos os dados necessários para a pesquisa. Assim, a amostra compreendeu as 21 companhias restantes. Destaca-se que, para consecução do objetivo do estudo, as empresas da amostra foram classificadas em dois grupos distintos: um deles compreende as empresas familiares e o segundo compreende as empresas não familiares.

As características observadas nesta pesquisa para considerar uma companhia como familiar foram a concentração de propriedade com uma família e/ou a participação dos membros da família no conselho por serem as características mais utilizadas pelos pesquisadores (ANDERSON; REEB, 2003; LEONE, 2005; SHYU, 2011). O percentual de concentração mínimo de ações com uma família considerado para determinar a empresa como familiar foi de $20 \%$ por ser um percentual significativamente utilizado pela literatura.

\subsection{COLETA E ANÁLISE DOS DADOS}

Os dados da pesquisa são compostos por dados primários e secundários. Os dados primários compreendem aqueles relacionados à caracterização das empresas 
familiares. Para a identificação das empresas familiares utilizou-se o Formulário de Referência disponível no sítio da CVM e da BM\&FBovespa, no item 15.1/2, para a participação familiar no capital, e nos itens 12.6/8 e 12.9 para a participação familiar na gestão da companhia. Os dados relacionados ao desempenho das empresas são de caráter secundário, sendo sua coleta realizada na base de dados Economática ${ }^{\circledR}$ para o período de 2010 a 2012. As variáveis utilizadas são apresentadas no Quadro 2 - Variáveis utilizadas no estudo.

Quadro 2. Variáveis utilizadas no estudo.

\begin{tabular}{|l|c|c|}
\hline VARIÁVEIS & SIGLA & FÓRMULA \\
\hline Rentabilidade sobre o ativo & ROA & Lucro Líquido / Ativo Total \\
\hline Rentabilidade sobre o Patrimônio Líquido & ROE & $\begin{array}{c}\text { Lucro Líquido / Patrimônio } \\
\text { Líquido }\end{array}$ \\
\hline $\begin{array}{l}\text { Margem líquida / Rentabilidade sobre as } \\
\text { vendas }\end{array}$ & ROS & Lucro Líquido / Receita Líquida \\
\hline
\end{tabular}

Fonte: Dados da Pesquisa.

O ROE é obtido através da divisão do resultado líquido pelo Patrimônio Líquido da empresa. Segundo Gitman (2004), o ROE mensura o retorno sobre o investimento dos proprietários da empresa. Quanto maior for o resultado obtido nesse indicador, em melhor situação a empresa se encontrará (GITMAN, 2004).

Já o ROA é obtido através da divisão do resultado líquido pelos ativos totais da empresa. Segundo Capobiango et al. (2012), o ROA mede a eficiência da empresa na geração de lucros com seus ativos totais. Ainda, segundo Gitman (2004), quanto maior for o rendimento da empresa sobre o total de ativos, melhor.

O ROS ou Margem Líquida, por sua vez, é obtido pela divisão do Resultado Líquido pela Receita Líquida, medida em porcentagem. Segundo Gitman (2004), a margem líquida mensura o percentual de dinheiro proveniente das vendas que resta após todos os custos e despesas, incluindo impostos, serem deduzidos. Ainda segundo o mesmo autor, a margem líquida é uma medida usualmente citada em relação ao sucesso da empresa a respeito do lucro sobre as vendas.

Esses três indicadores foram utilizados no presente estudo, visto que indicam o retorno gerado para os investidores, dos ativos da empresa e a contribuição 
das receitas ao resultado. Segundo Camargos e Barbosa (2005), os indicadores de rentabilidade visam identificar a situação econômica das empresas, pois fornecem o retorno proporcionado pelo negócio, sinalizando a eficiência da sua gestão.

Para verificar o desempenho das empresas do agronegócio brasileiro utilizou-se a Análise Envoltória de Dados (DEA). O DEA converte várias saídas e entradas em uma escala de medida de eficiência e constrói, a partir de então, uma fronteira não paramétrica das DMUs que possuem uma eficiência ótima sobre um conjunto de dados permitindo uma medida de eficiência comparativa, gerando assim, uma escala de eficiência relativa para o grupo analisado (HU; QI; YANG, 2012).

Charnes, Cooper e Rhodes (1978) foram os precursores do modelo DEA conhecido na literatura como modelo CCR. Posteriormente, em 1984, Banker, Charnes e Cooper aprimoraram o modelo CCR dando origem ao modelo BCC. O modelo CCR avalia a eficiência total, determina as DMUs eficientes e qual a distância entre a fronteira de eficiência e as DMUs não eficientes, ou seja, o grau de não eficiência das demais DMUs. O modelo BCC "[...] permite a projeção de cada DMU ineficiente sobre a superfície de fronteira (envoltória) determinada pelas DMUs eficientes de tamanho compatível" (MACEDO; BARBOSA; CAVALCANTE, 2009, p. 68).

$O$ DEA produz um indicador que varia de 0 a 1 . Quanto mais próximo a 1 , mais eficiente é considerada a DMU, e escores iguais a 1 indicam eficiência (MACEDO; BARBOSA; CAVALCANTE, 2009). Assim, é possível avaliar quantas DMUs são eficientes e aquelas que não são eficientes e, para essas, as DMUs que lhes servem de referência para aumento de eficiência.

Como as variáveis de desempenho utilizadas no estudo são da ordem de quanto maior, melhor, o DEA é aplicado admitindo-se como Output todas as informações contidas nos numeradores dos índices, e como Input, as informações contidas no denominador do índice. No primeiro momento da pesquisa o DEA é aplicado separadamente em cada um dos grupos formados - familiar e não familiar - para identificação das empresas eficientes dentro de cada um dos grupos.

Como o DEA fornece a eficiência relativa, ou seja, a eficiência das empresas em relação ao grupo, para se verificar a relação da propriedade familiar com o desempenho das empresas o DEA foi aplicado a toda a amostra com o intuito de se identificar o escore de eficiência destas companhias. Então, para comparação entre 
os grupos - familiar e não familiar, aplicou-se o teste ANOVA.

\section{RESULTADO E DISCUSSÃO}

Nesta seção apresenta-se a descrição e análise dos resultados da pesquisa. Inicialmente são apresentados os escores de eficiência e os benchmarks das empresas familiares obtidos a partir da aplicação do DEA. Os resultados são apresentados na Tabela 1, Escore de eficiência e benchmarks das empresas familiares.

Tabela 1. Escore de eficiência e benchmarks das empresas familiares.

(continua)

\begin{tabular}{|c|c|c|c|c|c|c|c|}
\hline Empresas & 2010 & Benchmark & \multicolumn{2}{|c|}{2011 Benchmark } & 2012 & Benchmark & Média \\
\hline Laep & 1,00 & - & 1,00 & - & 1,00 & - & 1,00 \\
\hline Renar & 1,00 & - & 1,00 & - & 1,00 & - & 1,00 \\
\hline M.Diasbranco & 1,00 & - & 0,87 & Cosan; Laep & 1,00 & - & 0,96 \\
\hline Cosan & 0,83 & M.Diasbranco & 1,00 & - & 1,00 & - & 0,94 \\
\hline Oderich & 1,00 & - & 0,38 & Laep; Renar & 1,00 & - & 0,79 \\
\hline J. Macedo & 1,00 & - & 0,31 & Laep; Renar & 0,96 & $\begin{array}{c}\text { M.Diasbranco } \\
\text { Oderich }\end{array}$ & 0,76 \\
\hline Cosan Ltd & 0,49 & M.Diasbranco & 0,70 & Cosan; Laep & 0,64 & $\begin{array}{l}\text { Cosan; M.Di- } \\
\text { asbranco }\end{array}$ & 0,61 \\
\hline São Martinho & 0,93 & $\begin{array}{l}\text { J. Macedo; } \\
\text { M.Diasbranco }\end{array}$ & 0,39 & Cosan; Laep & 0,42 & $\begin{array}{c}\text { M.Diasbranco } \\
\text { Renar }\end{array}$ & 0,58 \\
\hline JBS & 0,32 & M.Diasbranco & 0,03 & Cosan & 1,00 & - & 0,45 \\
\hline Marfrig & 0,42 & M.Diasbranco & 0,30 & Cosan; Laep & 0,24 & $\begin{array}{l}\text { Cosan; M.Di- } \\
\text { asbranco }\end{array}$ & 0,32 \\
\hline V-Agro & 0,24 & $\begin{array}{l}\text { J. Macedo; } \\
\text { M.Diasbranco }\end{array}$ & 0,27 & Cosan; Laep & 0,38 & $\begin{array}{c}\text { M.Diasbranco; } \\
\text { Renar }\end{array}$ & 0,30 \\
\hline Josapar & 0,26 & $\begin{array}{l}\text { M.Diasbranco; } \\
\text { Oderich }\end{array}$ & 0,10 & Laep; Renar & 0,52 & $\begin{array}{l}\text { M.Diasbranco; } \\
\text { Oderich }\end{array}$ & 0,29 \\
\hline Minerva & 0,26 & $\begin{array}{l}\text { M.Diasbranco; } \\
\text { Oderich }\end{array}$ & 0,18 & Cosan; Laep & 0,37 & $\begin{array}{c}\text { M.Diasbranco; } \\
\text { Oderich }\end{array}$ & 0,27 \\
\hline
\end{tabular}




\begin{tabular}{|c|c|c|c|c|c|c|c|}
\hline \multicolumn{8}{|c|}{ (conclusão) } \\
\hline SLC Agrícola & 0,24 & $\begin{array}{l}\text { J. Macedo; } \\
\text { M.Diasbranco }\end{array}$ & 0,25 & Cosan; Laep & 0,30 & $\begin{array}{l}\text { M.Diasbranco; } \\
\text { Renar }\end{array}$ & 0,26 \\
\hline Tereos & 0,56 & M.Diasbranco & 0,15 & Cosan; Laep & 0,05 & $\begin{array}{l}\text { Cosan; M.Di- } \\
\text { asbranco }\end{array}$ & 0,25 \\
\hline Média & 0,64 & & 0,46 & & 0,66 & & 0,59 \\
\hline
\end{tabular}

Fonte: Dados da pesquisa.

Conforme verificado na Tabela 1 , as empresas Laep e Renar foram eficientes quanto ao seu desempenho nos três anos analisados. As companhias M. Diasbranco, Cosan e Oderich foram consideradas eficientes em dois dos três anos analisados; entretanto, destaca-se que a empresa Oderich apresentou baixa eficiência no exercício de 2011, situação atípica se comparada a 2010 e 2012.

A empresa M.Diasbranco destaca-se entre as empresas familiares por ter sido eficiente em dois dos três anos analisados e ter eficiência média próxima a $100 \%$ e ter sido considerada benchmark para todas as empresas não eficientes nos anos de 2010 e 2012 . De modo geral a eficiência média das empresas familiares do agronegócio que compõem a amostra desta pesquisa é de aproximadamente $60 \%$. $53 \%$ das empresas familiares apresentaram eficiência média do período inferior à média do grupo e apenas duas companhias foram eficientes nos três anos.

Destaca-se que as empresas Tereos, SLC Agrícola, Minerva e Josapar apresentaram os menores índices de eficiência, sendo estes próximos a 30\%. A partir dos resultados da Tabela 1, verifica-se que as empresas familiares, em sua maioria, não são eficientes. Os resultados quanto à aplicação do DEA para as empresas não familiares são apresentados na Tabela 2, Escore de eficiência das empresas não familiares.

Tabela 2. Escore de eficiência das empresas não familiares.

(continua)

\begin{tabular}{l|c|c|c|c|c|c|c}
\hline Empresas & $\mathbf{2 0 1 0}$ & Benchmark & $\mathbf{2 0 1 1}$ & Benchmark & $\mathbf{2 0 1 2}$ & \multicolumn{1}{c}{ Benchmark } & \multicolumn{1}{c}{ Média } \\
\hline BRF S.A. & 1,00 & - & 1,00 & & 1,00 & & 1,00 \\
Excelsior & 1,00 & - & 1,00 & & 1,00 & & 1,00
\end{tabular}




\begin{tabular}{|c|c|c|c|c|c|c|c|}
\hline \multicolumn{6}{|c|}{ (conclusão) } & & \\
\hline $\begin{array}{l}\text { Iguaçu } \\
\text { Café }\end{array}$ & 0,78 & $\begin{array}{l}\text { Biosev; Excel- } \\
\text { sior }\end{array}$ & 1,00 & & 1,00 & & 0,93 \\
\hline Minupar & 1,00 & - & 0,44 & $\begin{array}{l}\text { BRF S.A.; } \\
\text { Excelsior }\end{array}$ & 1,00 & & 0,81 \\
\hline Biosev & 1,00 & & 0,38 & $\begin{array}{l}\text { BRF S.A.; } \\
\text { Excelsior }\end{array}$ & 0,46 & $\begin{array}{l}\text { BRF S.A.; Excel- } \\
\text { sior }\end{array}$ & 0,61 \\
\hline Cacique & 0,80 & $\begin{array}{l}\text { Biosev; Excel- } \\
\text { sior }\end{array}$ & 0,23 & $\begin{array}{l}\text { BRF S.A.; } \\
\text { Excelsior }\end{array}$ & 0,72 & $\begin{array}{l}\text { BRF S.A.; Excel- } \\
\text { sior }\end{array}$ & 0,59 \\
\hline Média & 0,93 & & 0,68 & & 0,86 & & 0,82 \\
\hline
\end{tabular}

Fonte: Dados da pesquisa.

A Tabela 2 evidencia que as empresas BRF S.A. e Excelsior foram eficientes nos três anos analisados, e a Companhia Iguaçu Café mostrou-se eficiente em dois dos três anos analisados, tendo eficiência média no período próximo a $100 \%$. A eficiência média das empresas não familiares, para o período de 2010 a 2012, foi de $82 \% .50 \%$ da amostra de empresas não familiares apresentou eficiência inferior à média. De modo geral os resultados indicam que as empresas não familiares possuem uma alta eficiência. A empresa Excelsior destaca-se entre as empresas não familiares por ter sido eficiente nos três anos analisados e ser considerada como benchmark para todas aquelas consideradas não eficientes.

Devido ao DEA apresentar a eficiência relativa das empresas, para ser possível a comparação dos grupos de empresas - familiar e não familiar - aplicou-se o DEA para todas as empresas da amostra, em conjunto, a fim de identificar aquelas eficientes e não eficientes para posterior comparação dos grupos. Os resultados da eficiência para as empresas familiares e não familiares são apresentados na Tabela 3, Escore de eficiência das empresas familiares e não familiares. 
Tabela 3. Escore de eficiência das empresas familiares e não familiares.

(continua)

\begin{tabular}{|c|c|c|c|c|c|c|c|c|}
\hline \multirow[b]{2}{*}{ Empresas } & \multirow[b]{2}{*}{ Classificação } & \multicolumn{7}{|c|}{ Escores e Benchmarks } \\
\hline & & 2010 & $\begin{array}{c}\text { Bench- } \\
\text { mark }\end{array}$ & 2011 & $\begin{array}{l}\text { Bench- } \\
\text { mark }\end{array}$ & 2012 & Benchmark & Média \\
\hline Excelsior & Não Familiar & 1,00 & - & 1,00 & - & 1,00 & - & 1,00 \\
\hline $\begin{array}{l}\text { Iguaçu } \\
\text { Café }\end{array}$ & Não Familiar & 1,00 & - & 1,00 & - & 1,00 & - & 1,00 \\
\hline Laep & Familiar & 1,00 & - & 1,00 & - & 1,00 & - & 1,00 \\
\hline Renar & Familiar & 1,00 & - & 1,00 & - & 1,00 & - & 1,00 \\
\hline Cosan & Familiar & 1,00 & - & 1,00 & - & 0,90 & $\begin{array}{c}\text { BRF S.A.; } \\
\text { M.Diasbran- } \\
\text { co }\end{array}$ & 0,97 \\
\hline $\begin{array}{l}\text { M.Dias- } \\
\text { branco }\end{array}$ & Familiar & 0,87 & $\begin{array}{l}\text { Cosan; } \\
\text { Laep }\end{array}$ & 0,87 & $\begin{array}{l}\text { Cosan; } \\
\text { Laep }\end{array}$ & 1,00 & - & 0,91 \\
\hline BRF S.A. & Não Familiar & 0,56 & Cosan & 0,56 & Cosan & 1,00 & - & 0,70 \\
\hline Cosan Ltd & Familiar & 0,70 & $\begin{array}{l}\text { Cosan; } \\
\text { Laep }\end{array}$ & 0,70 & $\begin{array}{l}\text { Cosan; } \\
\text { Laep }\end{array}$ & 0,60 & $\begin{array}{c}\text { BRF S.A.; } \\
\text { M.Diasbran- } \\
\text { co }\end{array}$ & 0,67 \\
\hline Minupar & Não Familiar & 0,37 & $\begin{array}{l}\text { Excel- } \\
\text { sior; } \\
\text { Laep }\end{array}$ & 0,37 & $\begin{array}{l}\text { Excelsior; } \\
\text { Laep }\end{array}$ & 1,00 & - & 0,58 \\
\hline J. Macedo & Familiar & 0,24 & $\begin{array}{l}\text { Excel- } \\
\text { sior; } \\
\text { Laep }\end{array}$ & 0,24 & $\begin{array}{l}\text { Excelsior; } \\
\text { Laep }\end{array}$ & 0,81 & $\begin{array}{l}\text { Excelsior; } \\
\text { M.Diasbran- } \\
\text { co }\end{array}$ & 0,43 \\
\hline $\begin{array}{l}\text { São Mar- } \\
\text { tinho }\end{array}$ & Familiar & 0,39 & $\begin{array}{l}\text { Cosan; } \\
\text { Laep }\end{array}$ & 0,39 & $\begin{array}{l}\text { Cosan; } \\
\text { Laep }\end{array}$ & 0,38 & $\begin{array}{l}\text { Excelsior; } \\
\text { M.Diasbran- } \\
\text { co }\end{array}$ & 0,39 \\
\hline JBS & Familiar & 0,03 & Cosan & 0,03 & Cosan & 0,88 & BRF S.A. & 0,31 \\
\hline V-Agro & Familiar & 0,27 & $\begin{array}{l}\text { Cosan; } \\
\text { Laep }\end{array}$ & 0,27 & $\begin{array}{l}\text { Cosan; } \\
\text { Laep }\end{array}$ & 0,36 & $\begin{array}{l}\text { Excelsior; } \\
\text { M.Diasbran- } \\
\text { co }\end{array}$ & 0,30 \\
\hline Marfrig & Familiar & 0,30 & $\begin{array}{l}\text { Cosan; } \\
\text { Laep }\end{array}$ & 0,30 & $\begin{array}{l}\text { Cosan; } \\
\text { Laep }\end{array}$ & 0,23 & $\begin{array}{l}\text { BRF S.A.; } \\
\text { M.Diasbran- } \\
\text { co }\end{array}$ & 0,28 \\
\hline Biosev & Não Familiar & 0,24 & $\begin{array}{l}\text { Cosan; } \\
\text { Laep }\end{array}$ & 0,24 & $\begin{array}{l}\text { Cosan; } \\
\text { Laep }\end{array}$ & 0,36 & $\begin{array}{l}\text { BRF S.A.; } \\
\text { M.Diasbran- } \\
\text { co }\end{array}$ & 0,28 \\
\hline $\begin{array}{l}\text { SLC } \\
\text { Agrícola }\end{array}$ & Familiar & 0,25 & $\begin{array}{l}\text { Cosan; } \\
\text { Laep }\end{array}$ & 0,25 & $\begin{array}{l}\text { Cosan; } \\
\text { Laep }\end{array}$ & 0,27 & $\begin{array}{l}\text { Excelsior; } \\
\text { M.Diasbran- } \\
\text { co }\end{array}$ & 0,26 \\
\hline
\end{tabular}




\begin{tabular}{|c|c|c|c|c|c|c|c|c|}
\hline \multicolumn{9}{|c|}{ (conclusão) } \\
\hline Oderich & Familiar & 0,20 & $\begin{array}{l}\text { Excel- } \\
\text { sior; } \\
\text { Laep }\end{array}$ & 0,20 & $\begin{array}{l}\text { Excelsior; } \\
\text { Laep }\end{array}$ & 0,37 & $\begin{array}{l}\text { Excelsior; } \\
\text { M.Diasbran- } \\
\text { co }\end{array}$ & 0,25 \\
\hline Minerva & Familiar & 0,18 & $\begin{array}{c}\text { Cosan; } \\
\text { Laep }\end{array}$ & 0,18 & $\begin{array}{c}\text { Cosan; } \\
\text { Laep }\end{array}$ & 0,36 & $\begin{array}{c}\text { Excelsior; } \\
\text { M.Diasbran- } \\
\text { co }\end{array}$ & 0,24 \\
\hline Josapar & Familiar & 0,09 & $\begin{array}{l}\text { Excel- } \\
\text { sior; } \\
\text { Laep }\end{array}$ & 0,09 & $\begin{array}{l}\text { Excelsior; } \\
\text { Laep }\end{array}$ & 0,44 & $\begin{array}{c}\text { Excelsior; } \\
\text { M.Diasbran- } \\
\text { co }\end{array}$ & 0,21 \\
\hline Cacique & Não Familiar & 0,08 & $\begin{array}{l}\text { Excel- } \\
\text { sior; } \\
\text { Laep }\end{array}$ & 0,08 & $\begin{array}{l}\text { Excelsior; } \\
\text { Laep }\end{array}$ & 0,25 & $\begin{array}{c}\text { Excelsior; } \\
\text { M.Diasbran- } \\
\text { co }\end{array}$ & 0,14 \\
\hline Tereos & Familiar & 0,15 & $\begin{array}{c}\text { Cosan; } \\
\text { Laep }\end{array}$ & 0,15 & $\begin{array}{l}\text { Cosan; } \\
\text { Laep }\end{array}$ & 0,04 & $\begin{array}{c}\text { BRF S.A.; } \\
\text { M.Diasbran- } \\
\text { co }\end{array}$ & 0,11 \\
\hline Média & & 0,47 & & 0,47 & & 0,63 & & 0,53 \\
\hline
\end{tabular}

Fonte: Dados da pesquisa.

Conforme verificado na Tabela 3, as empresas Excelsior, Iguaçu Café, Laep e Renar foram eficientes nos três exercícios, tendo por base todas as empresas da amostra, todas estas também eficientes dentro de seus grupos (familiar ou não familiar). Dentre as empresas não familiares, a BRF, considerada eficiente no seu grupo (não familiar) apresentou-se como não eficiente em dois dos três anos quando analisada juntamente com as empresas familiares.

A Tabela 3 demonstra que há tanto empresas familiares quanto não familiares consideradas eficientes bem como não eficientes. As empresas menos eficientes foram as empresas Tereos, Cacique e Josapar, apresentando escores de eficiência médio inferior a $25 \%$ e, em ao menos um dos anos analisados, próximo a zero.

As empresas Cosan e M.Diasbranco apresentaram eficiência média próxima a 100\%, tendo a Cosan sido eficiente em dois dos três anos analisados e a M. Diasbranco eficiente em 2012. De modo geral, para o período, a eficiência média da amostra analisada é de 53\%. Das 25 analisadas, 48\% apresentaram eficiência abaixo da média, destas 10 familiares e 2 não familiares, ou seja, 66,67\% das empresas familiares apresentam eficiência abaixo da média do grupo enquanto apenas 33,33\% das empresas não familiares apresentaram eficiência média inferior à média do grupo para o período analisado. 
Os resultados expressos na Tabela 3 fornecem indicativos de que as empresas familiares do agronegócio que compõem a amostra desta pesquisa possuem menor eficiência quanto ao seu desempenho quando comparadas às empresas não familiares. Para confirmação do resultado aplicou-se a técnica estatística. Antes da apresentação do resultado da ANOVA, apresenta-se a média da eficiência dos grupos para o período de 2010 a 2012 na Tabela 4, Média da eficiência das empresas analisadas, tomando por base os escores de eficiente da Tabela 3.

Tabela 4. Média da eficiência das empresas analisadas.

\begin{tabular}{c|c|c|c|c}
\hline \multirow{2}{*}{ Classificação } & \multicolumn{4}{|c}{ Média } \\
\cline { 2 - 5 } & $\mathbf{2 0 1 0}$ & $\mathbf{2 0 1 1}$ & $\mathbf{2 0 1 2}$ & Período \\
\hline Familiar & 0,445398 & 0,44539833 & 0,57607 & 0,488955 \\
Não Familiar & 0,539982 & 0,53998167 & 0,769231 & 0,616398 \\
\hline
\end{tabular}

Fonte: Dados da pesquisa.

Como observado na Tabela 4, em todos os anos analisados as empresas não familiares apresentaram eficiência superior às empresas familiares. Estes resultados demonstram que as empresas não familiares possuem desempenho médio superior àquelas empresas sob controle ou gestão familiar. Destaca-se ainda que a média das empresas não familiares é superior à média da amostra total. Já as empresas familiares apresentam média inferior à amostra total, descrita na Tabela 3.

Os resultados expostos fornecem indicativo para sustentar o argumento de Saravanan (2009) de que a participação familiar pode prejudicar a empresa devido à família tender a priorizar seus interesses em detrimento dos interesses da companhia contribuindo para a descapitalização da empresa, prejudicando seu resultado. Entretanto, deve-se destacar que, conforme Chami (2001) e Shyu (2011), as famílias possuem visão de longo prazo quanto aos seus investimentos e que, nesta pesquisa, foram avaliadas variáveis de desempenho dentro do curto prazo.

Inclui a esta questão que os gestores, para as empresas com gestão profissionalizada, na qual se inserem as empresas não familiares, o gestor é contratado, geralmente, para atuar por tempo determinado e, assim, tende a priorizar decisões que impactam positivamente o resultado da companhia no seu curto prazo, não tendo maior interesse no impacto de suas decisões no longo prazo para a compa- 
nhia, diferentemente dos proprietários, que têm perspectivas de longo prazo com a companhia na qual depositam seu capital (JENSEN; SMITH JUNIOR, 1985). Este argumento, apresentado por Jensen e Smith Junior (1985), fornece respaldo para o resultado exposto na Tabela 4, visto que indica o desempenho das companhias no seu curto prazo, que é de maior interesse aos gestores das empresas não familiares. Para confirmação do resultado exposto na Tabela 4, aplicou-se a técnica estatística ANOVA, cujo resultado é exposto na Tabela 5, Resultado do teste ANOVA.

Tabela 5. Resultado do teste ANOVA.

\begin{tabular}{c|c|c|c}
\hline & Soma dos quadrados & \multicolumn{1}{c}{ F } & p-value \\
\hline Entre grupos & 0,209 & 1,664 & 0,202 \\
Nos grupos & 7,655 & & \\
\hline Teste de Levene & $0,561 \quad$ p-value $=0,457$ \\
Teste de Welch & $1,560 \quad$ p-value $=0,222$ & \\
\hline
\end{tabular}

Fonte: Dados da pesquisa.

Os testes de Levene e de Welch, relatados na Tabela 5, apresentaram valor $\mathrm{p}$ ( $p$-value) superior a 5\%, indicando que não há heterogeneidade na variância das variáveis analisadas nos grupos de análise - familiar e não familiar - atendendo aos pressupostos do teste ANOVA, confirmando que a técnica estatística pode ser utilizada nesta amostra.

O resultado exposto na Tabela 5 indica que a diferença de média entre os grupos não é significativa, assim, apesar de a Tabela 4 indicar que as empresas não familiares são mais eficientes que as empresas familiares quanto ao seu desempenho, esta diferença quanto à eficiência não é significante. Este resultado pode estar influenciado pela baixa presença de empresas não familiares na amostra desta pesquisa, entretanto, oferece indicativos para apoiar a literatura quanto a maior eficiência das empresas não familiares em relação às empresas familiares no curto prazo.

\section{CONSIDERAÇÕES FINAIS}

Esta pesquisa objetivou verificar a relação da propriedade familiar com o desempenho de empresas do agronegócio brasileiro. Para tanto, fez-se uso de uma 
pesquisa descritiva com abordagem quantitativa em uma amostra de 25 empresas listadas na BM\&FBovespa no período de 2010 a 2012.

Para consecução do objetivo aplicou-se primeiramente a Análise Envoltória de Dados (DEA) a fim de identificar a eficiência quanto ao desempenho das empresas familiares e não familiares; posteriormente aplicou-se a técnica estatística ANOVA a fim de verificar se as empresas familiares apresentavam maior ou menor eficiência em relação ao seu desempenho quando comparadas às empresas não familiares.

Os resultados da pesquisa indicaram que as empresas Excelsior, Iguaçu Café, Laep e Renar foram eficientes nos três anos analisados tanto em seus grupos (familiar ou não familiar) quanto em relação à amostra total. Os resultados indicaram também que as empresas Tereos, Cacique e Josapar; apresentaram-se como as menos eficientes tanto para a amostra total como nos grupos, tendo seus escores de eficiência média inferiores a $25 \%$ e, em ao menos um dos anos analisados, próximo a zero.

Apesar de não significativos, os resultados apresentam indicativos de que as empresas não familiares são mais eficientes que as empresas familiares quanto ao desempenho de curto prazo. Estes resultados encontram respaldo na literatura de que as empresas familiares apresentam perspectivas de desempenho de longo prazo, e as não familiares, cuja gestão é profissionalizada, priorizam desempenho de curto prazo.

$\mathrm{Na}$ realização do estudo, surgiram limitações que não permitiram a análise do total da população sugerida. Algumas empresas não puderam ser operacionalizadas, uma vez que as informações contábeis referentes ao período analisado não estavam disponíveis, necessitando-se assim excluí-las da amostra. Além disso, a Análise Envoltória de Dados (DEA) é sensível ao número de Inputs e Outputs, assim como ao tamanho da amostra. Quando o número de empresas (DMUs) é pequeno em relação à soma do número de Inputs e Outputs, a média de eficiência da amostra aumenta, sendo assim, incrementar o número de Inputs e Outputs sem aumentar o tamanho da amostra também incrementará a eficiência média da amostra. Estas limitações não invalidam os resultados apresentados.

Recomenda-se, para futuros estudos, a análise do desempenho das empresas familiares em comparação às empresas não familiares tomando por base o de- 
sempenho de longo prazo. Além disso, sugere-se que este estudo seja aplicado em outras amostras para fins de comparação dos resultados.

\section{REFERÊNCIAS}

ANDERSON, R.C.; REEB, D.M. Founding-family ownership and firm performance: evidence from the S\&P 500. The Journal of Finance, v. 58, n. 3, p. 1301-1328, jun. 2003.

BANKER, R.D.; CHARNES, A.; COOPER, W.W. Some Models for Estimating Technical and Scale Inefficiencies in Data Envelopment Analysis. Management Science. v. 30, n. 9, p. 1078-1092, 1984.

CAMARGOS, M.A. de; BARBOSA, F.V. Análise do desempenho econômico-financeiro e da criação de sinergias em processos de fusões e aquisições do mercado brasileiro ocorridos entre 1995 e 1999. Caderno de Pesquisas em Administração, São Paulo, v. 12 , n. 2 , p. 99-115, abr./jun. 2005.

CAPOBIANGO, R.P.; ABRANTES, L.A.; FERREIRA, M.A.M.; FARONI, W. Desempenho financeiro: um estudo com empresas de três diferentes setores. Revista de C. Humanas, Viçosa, v. 12, n. 1, p. 165-180, jan./jun. 2012.

CENTRO DE ESTUDOS AVANÇADOS EM ECONOMIA APLICADA. CEPEA. Relatório PIBAgro-Brasil, 2012. Disponível em: < http://www.cepea.esalq.usp.br/comunicacao/Cepea_PIB_BR_dez12.pdf $>$. Acesso em: 17 set. 2013.

CERVO, A.L.; BERVIAN, P.A.; SILVA, R. da. Metodologia científica. 6. ed. São Paulo: Pearson Prentice Hall, 2007.

CHAMI, R. What is different about family business? Working Paper. [s.l.]: International Monetary Fund, 2001.

CHARNES, A.; COOPER, W.W.; RHODES, E. Measuring the Efficiency of Decision Making Units. European Journal of Operational Research, v. 2, n. 6, p. 429-444, 1978. 
COLLIS, J.; HUSSEY, R. Pesquisa em administração. 2. ed. Porto Alegre: Bookman, 2005.

FACCIO, M.; LANG, L.H.P. The ultimate ownership of western European corporations. Journal of Financial Economics, v. 65, n. 3, p. 365-395, set. 2002.

GIL, A. C. Métodos e técnicas de pesquisa social. 6. ed. São Paulo: Atlas, 2011.

GITMAN, L.J. Princípios de administração financeira. 10. ed. São Paulo: Pearson Addison Wesley, 2004.

HU, H.H.; QI, Q.; YANG, C.H. Analysis of hospital technical efficiency in China: Effect of health insurance reform. China Economic Review, v. 23, n. 4, p. 865-877, 2012.

JENSEN, M.C.; SMITH JUNIOR, C.W. Stockholder, manager, and creditor interests: applications of agency theory. In: ALTMAN, E.; SUBRAHMANYAM, M. Recent Advances in Corporate Finance. Homewood: Irwin Professional Publishing, 1985.

LEONE, N.M. de C.P.G. Sucessão na empresa familiar: preparando as mudanças para garantir sobrevivência no mercado globalizado. São Paulo: Atlas, 2005.

MACEDO, M.A.S.; BARBOSA, A.C.T.C.; CAVALCANTE, G.T.C. Desempenho de agências bancárias no Brasil: aplicando análise envoltória de dados (DEA) a indicadores relacionados às perspectivas do BSC. Revista Economia \& Gestão. v. 9, n. 19, p. 65-84, jan./abr. 2009.

MARCONI, M. de A.; LAKATOS, E.M. Técnicas de pesquisa: planejamento e execução de pesquisas, amostragens e técnicas de pesquisa, elaboração, análise e interpretação de dados. 7. ed. São Paulo: Atlas, 2012.

MARTÍNEZ, J.I.; STÖHR, B.S.; QUIROGA, B.F. Family ownership and firm performance: evidence from public companies in Chile. Family Business Review, v. 20, n. 2, p. 83-94. 2007.

MAURY, B. Family ownership and firm performance: empirical evidence from Western European corporations. Journal of Corporate Finance, v. 12, p. 321-341, 2006. 
ORO, I.M.; BEUREN, I.M.; HEIN, N. Análise da eficiência de empresas familiares brasileiras. RAE-eletrônica. v. 8, n. 2, p. 1-27, jul./dez. 2009.

PEREZ, M.M.; FAMÁ, R. Métodos de avaliação de empresas e o balanço de determinação. Administração em Diálogo, n. 6, p. 101-112, 2004.

RICHARDSON, R.J. Pesquisa social: métodos e técnicas. 3. ed. São Paulo: Atlas, 1999.

SAN MARTIN-REYNA, J. M.; DURAN-ENCALADA, J. A. The relationship among family business, corporate governance and firm performance: Evidence from the Mexican stock exchange. Journal of Family Business Strategy, v. 3, n. 2, p. 106-117, 2012.

SARAVANAN, P. Corporate governance characteristics and company performance of family owned and non-family owned business in India. Working paper: Indian Institute of Management, 2009.

SHYU, J. Family ownership and firm performance: evidence from Taiwanese firms. International Journal of Managerial Finance, v. 7, n. 4, p. 397-411, 2011.

SILVA, F.; MAJLUF, N. Does family ownership shape performance outcomes? Journal of Business Research, v. 61, p. 609-614, 2008.

USDA. United States Department of Agriculture. Economic Research Service 2013. Disponível em: <http://www.ers.usda.gov/topics/international-markets-trade/countries-regions/brazil/basic-information.aspx\#.Ujmfi8afhZQ $>$. Acesso em: 17 set. 2013.

WANDERLEY, C.A.N.; SILVA, A.C. da; LEAL, R.B. Tratamento Contábil de Ativos Biológicos e Produtos Agrícolas: uma Análise das Principais Empresas do Agronegócio Brasileiro. Pensar Contábil, v. 14, n. 53, p. 53-62, 2012.

Recebido em: 07 de outubro de 2013 Aceito em: 28 de julbo de 2014 